\title{
Prenatally diagnosed foramen ovale restriction in fetuses with hypoplastic left heart syndrome may be a predictor of longer hospitalization, but not of a need for an urgent Rashkind procedure
}

\author{
Lukasz Sokolowski ${ }^{1,2}$, Maria Respondek-Liberska9,3, Marek Pietryga ${ }^{4}$, Maciej Slodki 1,5 \\ ${ }^{1}$ Department of Prenatal Cardiology in Polish Mother's Memorial Hospital Research Institute, Lodz, Poland \\ ${ }^{2}$ Department of Obstetrics, Perinatology and Gynecology in Polish Mother's Memorial Hospital Research Institute, Lodz, Poland \\ ${ }^{3}$ Department of Diagnoses and Prevention Fetal Malformations Medical University of Lodz, Poland \\ ${ }^{4}$ Department of Obstetrics and Women's Diseases, Karol Marcinkowski University of Medical Sciences, Poznan, Poland \\ ${ }^{5}$ Faculty of Health Sciences, The State University of Applied Sciences in Plock, Poland
}

\begin{abstract}
Objectives: This prospective study aimed to assess the effectiveness of foramen ovale examination in classifying prenatal hypoplastic left heart syndrome (HLHS) in accordance with the new classification groupings for congenital heart defects.

Material and methods: The analysis included 145 fetuses with HLHS, diagnosed and monitored between 2008 and 2015 in Prenatal Cardiology Department at Polish Mother's Memorial Hospital Research Institute in Lodz. The main criteria for classifying our study population into three sub-groups was was the presence of a foramen ovale restriction, which we diagnosed by evaluating the diameter and blood flow through the foramen ovale. Of the total group, $73.8 \%(n=107)$ were classified as severe planned, $24.1 \%(n=35)$ as severe urgent, and $2.1 \%(n=3)$ as the severest group.

Results: Comparing the severe planned and the severe urgent HLHS groups showed: gestational age of delivery 38 vs 38 weeks respectively $(p=0.45)$; cesarean delivery $62 \%$ vs $79.2 \%(p=0.15)$; neonatal birth weight $3110 \mathrm{~g}$ vs $2985 \mathrm{~g}(\mathrm{p}=0.2)$; Apgar score 9 vs 9 points; survival rate $65.8 \%$ vs $61.9 \%(p=0.8)$; and hospitalization 38 vs 46.5 days $(p=0.059)$. Prenatal qualification for the group of severe urgent HLHS was characterized by $100 \%$ sensitivity, $80.6 \%$ specificity and a low positive predictive value of $9.5 \%$.

Conclusions:

1. Prenatal qualification into the group of severe urgent CHD based on the features of foramen ovale was characterized by high sensitivity, a satisfying specificity and a low positive predictive value.

2. Prenatally diagnosed foramen ovale restriction may be a predictor of longer hospitalization, but not of a need for an urgent Rashkind procedure.

3. New classifications of CHDs allowed clinicians to determine prognoses and to plan optimal multi-specialized care which resulted in similar outcomes between the severe planned and severe urgent HLHS groups.

Key words: heart defects; congenital; hypoplastic left heart syndrome; echocardiography; fetus; prenatal diagnosis
\end{abstract}

Ginekologia Polska 2019; 90, 1: 31-38

\section{INTRODUCTION}

Hypoplastic left heart syndrome (HLHS) is one of the most common congenital heart defect (CHD) diagnosed prenatally. According to data from the Polish Nationwide Registry of Fetal Cardiac Pathology (www.orpkp.pl) from the years 2004 to 2018, HLHS accounted for $9.1 \%$ of the 8317 CHDs diagnosed prenatally [1]. Due to the abnormal four-chamber cardiac view that is routinely seen when con- ducting the screening exam, the prenatal detection rate for HLHS is high [1, 2]. Patient management for HLHS in the fetus depends on the fetal hemodynamic status in the $3 \mathrm{rd}$ trimester of pregnancy. New classifications for CHDs primarily categorize HLHS according to the anticipated postnatal status of the newborn and on the assessed urgency for treatment [3-5]. As such, individual HLHS cases are assigned to one of the following three groups: 
- severe planned HLHS: HLHS does not require urgent postnatal treatment - the newborn is born in good condition and requires only prostaglandin E1 iv infusion, and can be prepared for the first stage of planned cardiac surgery

- severe urgent HLHS: HLHS requires, in addition to prostaglandin E1 iv infusion, urgent (first 24 hours) treatment in a catheterization laboratory (cath lab)

- severest HLHS: HLHS during the first minutes of postnatal life is cyanotic, does not respond to iv prostaglandin E1 infusion, and is deteriorating within minutes or within the next few hours.

Prenatal echocardiographic monitoring in the 3rd trimester allows qualification of the fetus or newborn into one of three groups. As a result, it is possible to set an optimal plan and synchronize the actions of obstetricians, neonatologists, pediatric cardiologists, interventional cardiologists and cardiac surgeons [6-8].

\section{Objectives}

This prospective study aimed to assess the effectiveness of foramen ovale examination in classifying prenatal HLHS in accordance with the new CHD classifications.

\section{MATERIAL AND METHODS}

The analysis included 145 fetuses with HLHS diagnosed and monitored in Prenatal Cardiology Department at Polish Mother's Memorial Hospital Research Institute in Lodz between 2008 and 2015. Of the total group, 73.8\% (107/145) were classified as severe planned, $24.1 \%$ (35/145) as severe urgent, and $2.1 \%$ (3/145) as the severest group (Fig. 1).

The criteria for assigning our study subjects to a particular group included evaluation of the foramen ovale (FO) restriction by echocardiographic fetal heart examination using parameters such as the FO diameter, maximum blood flow velocity through the FO and assessment of the blood flow spectra in the pulmonary veins. The severe planned cases of HLHS were determined when the FO diameter was greater than $3 \mathrm{~mm}$, the maximum blood flow velocity through the FO was less than $100 \mathrm{~cm} / \mathrm{s}$, and the pulmonary venous blood flow spectra was normal. The severe urgent cases were diagnosed when the FO diameter was $\leq 3 \mathrm{~mm}$, the maximum flow velocity through the FO was greater than or equal to $100 \mathrm{~cm} / \mathrm{s}$, and the blood flow spectra through the lung veins was assessed as abnormal. The features of the severest form of HLHS were complete closure of the FO, and no interatrial blood flow accompanied by an extremely abnormal pulmonary venous blood flow spectra. The results of the last fetal echocardiographic study before delivery were considered decisive.

In 25 of 145 diagnosed fetus cases, there was no data on the continuation of the pregnancy, nor any neonatal fol-

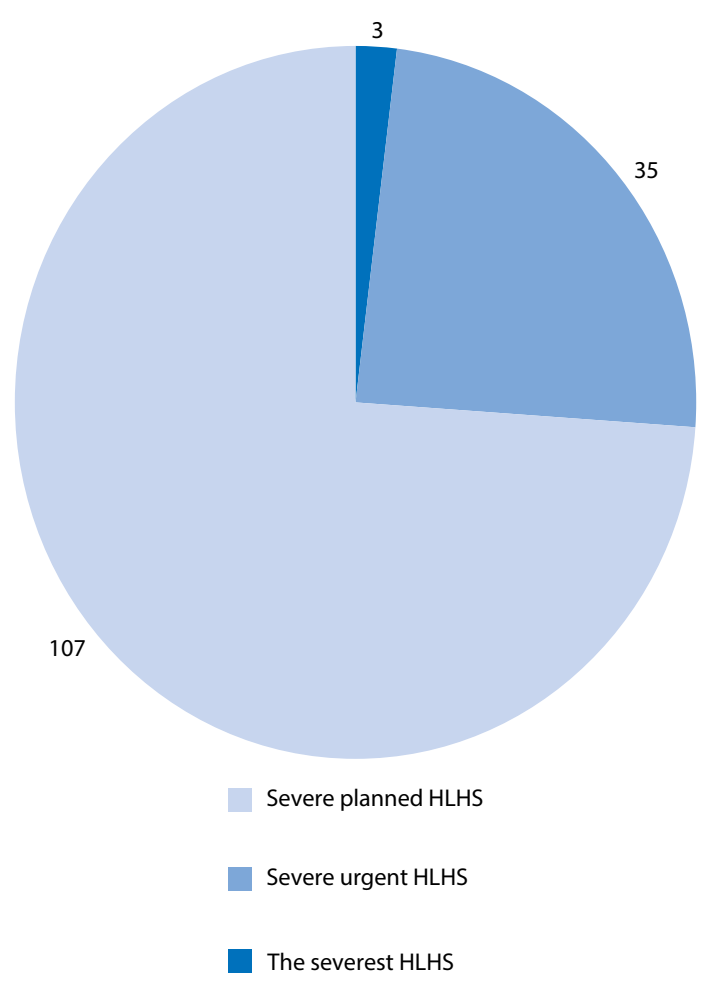

Figure 1. Prenatal classification of HLHS cases to respective risk groups

low-up data. Of the 120 gravidas for whom the follow-up data was available, 2 had decided to terminate their pregnancies (1.6\%). Both cases were classified as severe planned defects.

The study groups were compared using the following parameters: gestational age of delivery, percentage of caesarean deliveries, newborn's birth weight, Apgar score in the first minute of life, the percentage of cases requiring urgent treatment (defined as the need to perform the Rashkind procedure in the first day of postnatal life), survivability until discharge from the hospital, and days of hospitalization.

For nominal variables, percent values were calculated. For continuous variables with normal data distribution, mean values and standard deviations were calculated; and for continuous variables with non-normal data distribution median values were calculated. Nominal variables were compared using the Fisher test, and continuous variables were compared using the t-Student test in cases of normal data distribution, or, using the U Mann-Whitney test in cases of non-normal data distribution (Tab. 1).

\section{RESULTS}

In the severe planned HLHS group $(n=91)$ the median gestational age of delivery was 38 weeks (IQR 3740 weeks), which was similar to that of the severe urgent HLHS group ( $n=23)$, where the calculated median was 38 weeks (IQR 37-39 weeks) (U Mann-Whitney test $p=0.45$ ). In the severest HLHS group ( $n=2)$, one newborn was born at 36 weeks of gestation and the other at 39 weeks of gestation. 


\begin{tabular}{|c|c|c|c|}
\hline & Severe planned HLHS & $\begin{array}{l}\text { Severe urgent } \\
\text { HLHS }\end{array}$ & \\
\hline $\begin{array}{l}\text { Gestational age of delivery } \\
\text { (median) }\end{array}$ & $\begin{array}{l}38 \text { weeks } \\
\text { (IQR 37-40 weeks); } \\
(n=91)\end{array}$ & $\begin{array}{l}38 \text { weeks } \\
(\text { IQR 37-39 weeks); } \\
(n=23)\end{array}$ & $\begin{array}{l}P=0.45 \\
\text { (U Mann-Whitney test) }\end{array}$ \\
\hline Cesarean delivery & $62 \%(57 / 92)$ & $79.2 \%(19 / 24)$ & $P=0.15$ (Fisher test) \\
\hline $\begin{array}{l}\text { Birth weight (mean and } \\
\text { median) }\end{array}$ & $\begin{array}{l}\text { mean: } 3110 \mathrm{~g} \\
(\mathrm{SD} \pm 486 \mathrm{~g}) ; \\
\text { median: } 3150 \mathrm{~g} \\
(\mathrm{IQR} 2800-3400 \mathrm{~g}) ; \\
(\mathrm{n}=91)\end{array}$ & $\begin{array}{l}\text { mean: } 3050 \mathrm{~g} \\
(\mathrm{SD} \pm 425 \mathrm{~g}) ; \\
\text { median: } 2985 \mathrm{~g} \\
(\mathrm{IQR} 2770-3228 \mathrm{~g}) ;(\mathrm{n}=24)\end{array}$ & $\begin{array}{l}P=0.2 \\
\text { (U Mann-Whitney test) }\end{array}$ \\
\hline Apgar score (median) & $\begin{array}{l}9 \text { points } \\
\text { (IQR 8-9 points); }(n=89)\end{array}$ & $\begin{array}{l}9 \text { points } \\
\text { (IQR 9-9 points); } \\
(n=24)\end{array}$ & $\begin{array}{l}P=024 \\
\text { (U Mann-Whitney test) }\end{array}$ \\
\hline $\begin{array}{l}\text { Survival until hospital } \\
\text { discharge }\end{array}$ & $65.8 \%(52 / 79)$ & $61,9 \%(13 / 21)$ & $\begin{array}{l}P=0.8 \\
\text { (Fisher test) }\end{array}$ \\
\hline $\begin{array}{l}\text { Duration of hospitalization } \\
\text { (median) }\end{array}$ & $\begin{array}{l}38 \text { days } \\
\text { (IQR 31-46.5 days); }(n=49)\end{array}$ & $\begin{array}{l}46.5 \text { days } \\
\text { (IQR } 35.25-69.75 \text { days); } \\
(\mathrm{n}=12)\end{array}$ & $\begin{array}{l}P=0.059 \\
\text { (U Mann-Whitney test) }\end{array}$ \\
\hline
\end{tabular}

In the severe planned HLHS group, the percentage of cesarean deliveries was $62 \%$ (57/92), while in the severe urgent HLHS group it was $79.2 \%(19 / 24)$ (Fisher test $p=0.15)$. In the severest HLHS group, both patients had vaginal delivery.

In the severe planned HLHS group $(\mathrm{n}=91)$ the mean birth weight was $3110 \mathrm{~g}(\mathrm{SD} \pm 486 \mathrm{~g})$ and the median birth weight was $3150 \mathrm{~g}$ (IQR 2800-3400 g), while in the severe urgent HLHS group $(\mathrm{n}=24)$ the mean was $3050 \mathrm{~g}(\mathrm{SD} \pm 425 \mathrm{~g})$ and the median was $2985 \mathrm{~g}$ (IQR 2770-3228 g) (U Mann-Whitney test $p=0.2)$. In the severest HLHS group $(n=2)$, the birth weights were $2820 \mathrm{~g}$ and $3100 \mathrm{~g}$ (Tab. 1). In the severe planned HLHS group $(n=89)$ for whom we had Apgar data, the median Apgar score in the first minute of postnatal life was 9 points (IQR 8-9 points), which was similarly to the result for the severe urgent HLHS group $(n=24)$, where the value was 9 points (IQR 9-9 points) (U Mann-Whitney test $p=0.24$ ) (Tab. 1). Of the 2 cases in the severest HLHS group, one newborn scored 7 points, and the second 8 points on the Apgar scale. In 16 of 118 newborns, data regarding cardiological and cardiosurgical treatment was incomplete and therefore these cases were excluded from further analysis. The group of newborns with known cardiological and cardiosurgical follow-up history in the local database consisted of 102 patients. In this group 77.5\% (79/102) of cases were prenatally qualified as severe planned HLHS, $20.6 \%(21 / 102)$ as severe urgent HLHS and $1.9 \%(2 / 102)$ as the severest HLHS.

In the group of newborns classified prenatally as severe planned HLHS ( $n=79$ ), none required cardiac catheterization in the first day of life. Thus, it showed that the prenatal qualification of those fetuses was 100\% (79/79) consistent with the short-term postnatal clinical outcome.
In the group of newborns classified prenatally as severe urgent HLHS, only $9.5 \%$ (2/21) had cardiac catheterization (the Rashkind procedure) in the first day of postnatal life. Nineteen out of 21 (90.5\%) of these cases were confirmed to be severe planned HLHS based on postnatal paediatric cardiology examinations.

In the two cases of newborns classified prenatally as the severest HLHS, the qualification was correct, as both neonates died in the first day of postnatal life.

The efficiency of prenatal assessment of the foramen ovale in distinguishing between severe planned and severe urgent HLHS cases was evaluated. In our study group, there were:

- 2 fetuses with prenatally diagnosed severe urgent HLHS, which needed the Rashkind procedure in the first day of life (true positive cases)

- 19 fetuses with prenatally diagnosed severe urgent HLHS, which did not need the Rashkind procedure in the first day of life (false positive cases)

- 79 fetuses with prenatally diagnosed severe planned HLHS, which did not need the Rashkind procedure in the first day of life (true negative cases)

- No fetuses with prenatally diagnosed severe planned HLHS, which needed the Rashkind procedure in the first day of life (false negative cases).

The sensitivity of this method, defined as the number of true positive cases divided by the sum of the number of true positive cases and false negative cases was $100 \%$.

The specificity of this method, defined as the number of true negative cases divided by the sum of the number of true negative cases and false positive cases was $80.6 \%$.

The positive predictive value of this method, defined as the number of true positive cases divided by the sum of 


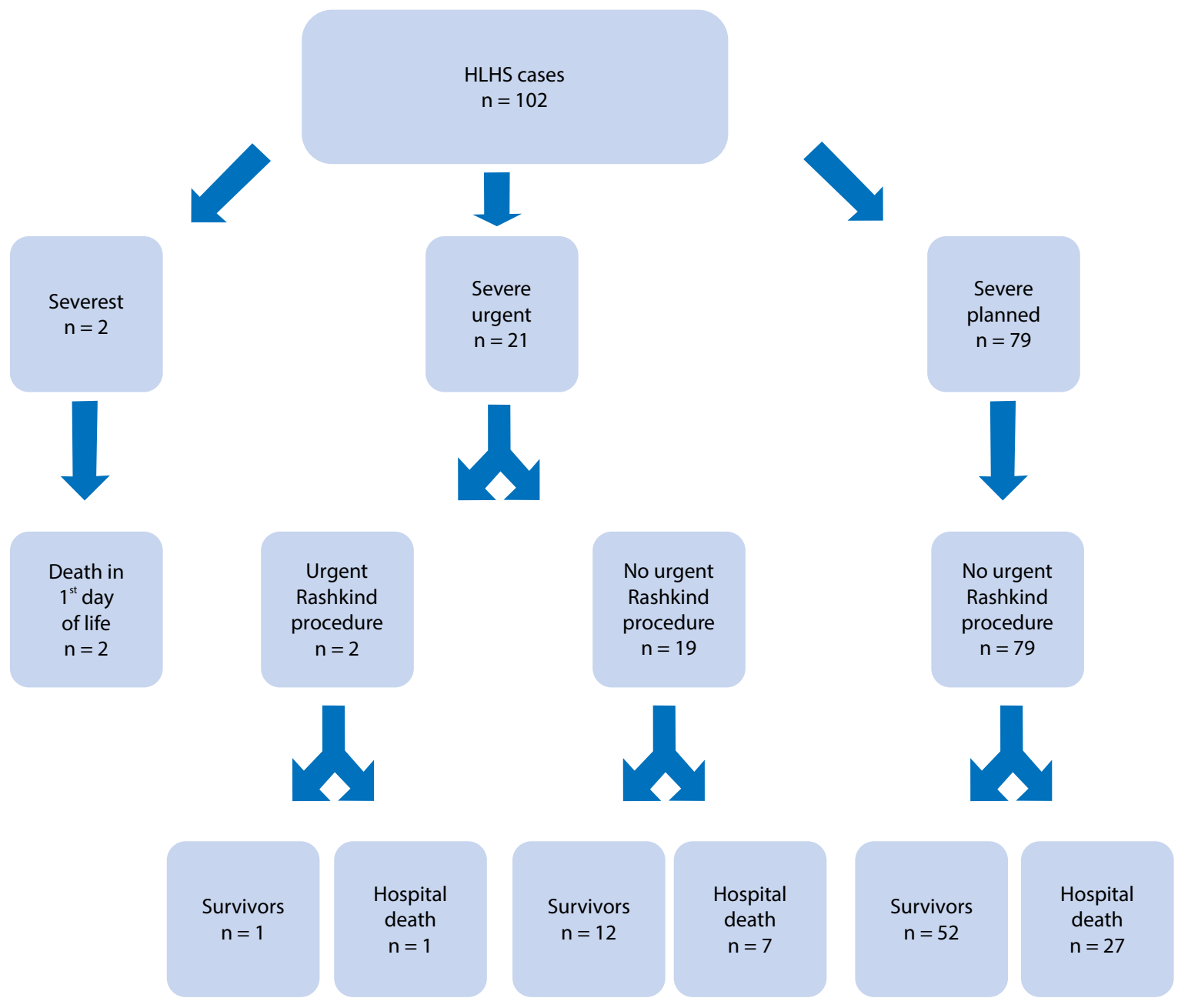

Figure 2. Postnatal follow-up of the respective HLHS groups

the number of true positive cases and false positive cases was $9.5 \%$.

In the group of newborns classified prenatally as severe planned HLHS the survival rate until hospital discharge was $65.8 \%$ (52/79), while in the severe urgent HLHS group the survival rate was $61.9 \%$ (13/21) (Fisher's test $p=0.8$ ) (Fig. 2).

In the group of patients with prenatally diagnosed severe planned HLHS who survived until hospital discharge $(n=49)$, the median duration of hospitalization was 38 days (IQR 31-46.5 days), while in the severe urgent HLHS group ( $n=12$ ) the median was 46.5 days (IQR 35.25-69.75 days) (U Mann-Whitney test $\mathrm{p}=0.059$ ).

\section{DISCUSSION}

Implementation of the new classifications of fetuses with congenital heart defects in several centers of prenatal cardiology around the world shows the need to introduce changes not only in the classification method, but also the consulting and management practices with fetal CHDs. Pruetz from Los Angeles divided patients with CHD into four classification groups with regard to the varying needs for emergency neonatal cardiac intervention (ENCI) [9]. According to his classifications, all cases of HLHS belong to the ENCl 3 group, which is characterized by the need for intravenous infusion of prostaglandin E1 and the possible need of urgent cardiac intervention $[3,4,9]$. The CHD classifications created by Respondek-Liberska and Slodki take into account the fact that fetuses and newborns with HLHS are not a homogeneous group of patients, and that instead, their hemodynamic state differs during the 3rd trimester of pregnancy, depending on the patency and size of the prenatally assessed foramen ovale $[5,7,8]$. Donofrio et al. from Washington reached the same conclusion and divided patients with HLHS into three groups which they called "Levels of Care" (LOC) groups [3]. In their classification, HLHS newborns with prenatally diagnosed non-restricted FO were assigned to LOC 2. According to Donofrio et al., the diagnosis of non-restricted FO is made by evaluating the ratio of the forward blood flow to the reversal flow Velocity Time Integral (VTI $f / r)$ in the pulmonary veins, measured using the Spectral Doppler. The ultrasound criterion of non-restricted FO is a VTI $\mathrm{f} / \mathrm{r}$ ratio $>5$. Due to the presence 
of a ductus-dependent CHD, the newborns in this group received an intravenous infusion of prostaglandin E1 to maintain patency of the ductus arteriosus, and they were prepared for the planned first stage of cardiosurgical treatment. In Respondek-Liberska and Slodki, the classification LOC 2 corresponded to a severe planned HLHS. Newborns with prenatally diagnosed restricted $\mathrm{FO}$ were assigned to LOC 3. The ultrasound criterion for inclusion in this LOC 3 group was a VTI $f / r$ ratio in pulmonary veins blood flow spectra of $<5$ to $>3$. In such cases, after delivery, the blood flow from the left to the right atrium is obstructed, which results in an insufficient volume of oxygenated blood getting into the systemic circulation. Blood pressure in the left atrium increases, leading to passive lung congestion and hemodynamic instability. In order to prevent this dramatic natural history, it is necessary to urgently widen the FO via balloon atrial septosomy (the Rashkind procedure) [10]. In the Respondek-Liberska and Slodki classification, LOC 3 corresponded to a severe urgent HLHS. Newborns with prenatally diagnosed extreme restriction of the FO or an intact atrial septum were assigned to the LOC 4 group (Fig. 3). The ultrasound criterion for inclusion in this group was a VTI $\mathrm{f} / \mathrm{r}$ ratio in pulmonary veins blood flow spectra of $<3$. The prognosis in such newborns is the most severe and in the Washington center the Rashkind procedure was performed in the first minute after birth in the delivery room $[3,4,11]$. Polish delivery rooms do not allow the performance of such necessary operations due to a lack of adequate facilities. If we want to give newborns with the severest HLHS a better chance of survival, we must make efforts to create multi-specialized delivery rooms combined with a catheterization laboratory [6]. An important issue is the fact that the prenatal diagnosis that assigns fetuses to one of the three mentioned groups is not final. In many cases HLHS is an evolving defect, meaning the restriction of the FO

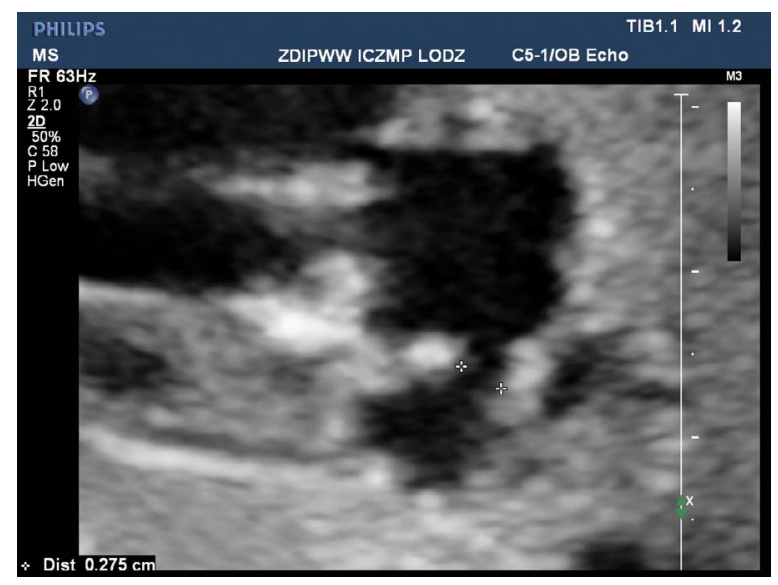

Figure 3. Prenatally predicted severe urgent $\mathrm{HLHS}$ with $\mathrm{FO}<3 \mathrm{~mm}$. Postnatally confirmed severe planned HLHS can develop and deepen during pregnancy. Accordingly, HLHS fetuses require serial echocardiographic monitoring. Therefore, in this group of patients fetal echocardiography is indicated to be performed at least every 4 weeks, and after the 36th week of gestation, with a frequency of up to every 7 days. Such a procedure allows us to predict the postnatal status of the newborn in the most accurate way [8]. In the newborns with a highly restrictive FO or intact atrial septum, the prognosis is worse than in the newborns with unobstructed inter-atrial communication, even if the Rashkind procedure is performed immediately after delivery. In American centers, the survival rate of the HLHS group with a highly restrictive FO or intact atrial septum, after the Rashkind procedure and the first stage of cardiac surgery was 33\%-48\% [12-14]. by comparison, the survival rate in the HLHS group without a restrictive FO was 74\% [15]. Furthermore, the FO restriction increases the blood pressure in the left atrium, which damages the pulmonary veins and leads to their arterialisation; and this process is already taking place during fetal life [13]. For this reason, attempts are being made to dilate a restrictive FO in utero, using either balloon atrial septostomy or stent implantation in the FO. However, according to data from the International Fetal Cardiac Intervention Registry database, prenatal treatment of FO restriction does not increase the survival rate up to the time of hospital discharge and is associated with a $13 \%$ risk of intrauterine fetal demise [16, 17]. More optimistic conclusions are drawn from the research conducted at the Boston center, where the six-month survival rate of patients treated in utero was significantly greater than for those in whom FO balloon septostomy was only performed after birth (69\% vs. $38 \%$, respectively) [10]. Intrauterine dilation of the FO to at least $3 \mathrm{~mm}$ was associated with better blood saturation and a lower incidence of postnatal balloon atrial septostomy [18].

Fetal echocardiographic examination enables us to predict the prenatal and postnatal hemodynamical state of the fetus and the newborn and to determine the necessity of urgent help $[3,19,20]$. According to current knowledge, the most precise method used to detect FO restriction is assesment of the blood flow in the pulmonary veins using the spectral Doppler technique. Restriction of the FO is associated with an increased blood pressure in the left atrium, which results in the occurrence of reversal blood flow in the pulmonary veins. The greater the narrowing of the FO, the greater the reversal blood flow. The Velocity Time Integral (VTI) is measured for the forward and the reversal pulmonary blood flow respectively. A forward to reversal VTI ratio (VTI f/r) of less than 5 and greater than 3 is associated with moderate FO restriction (Fig. 4), whereas a VTI f/r of less than 3 is present in severe FO restriction and intact atrial septum cases [21-23]. The method described above is character- 


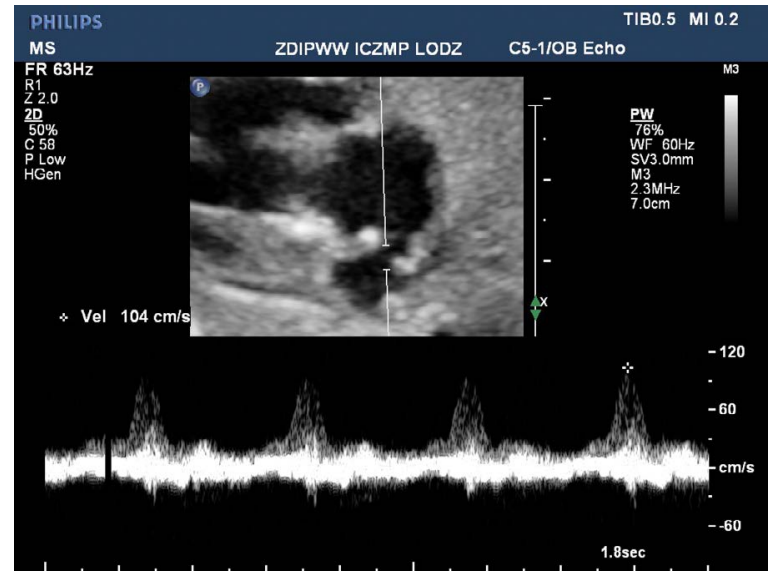

Figure 4. Prenatally predicted severe urgent HLHS with FO Vmax flow $>100 \mathrm{~cm} / \mathrm{s}$, Postnatally confirmed severe planed HLHS

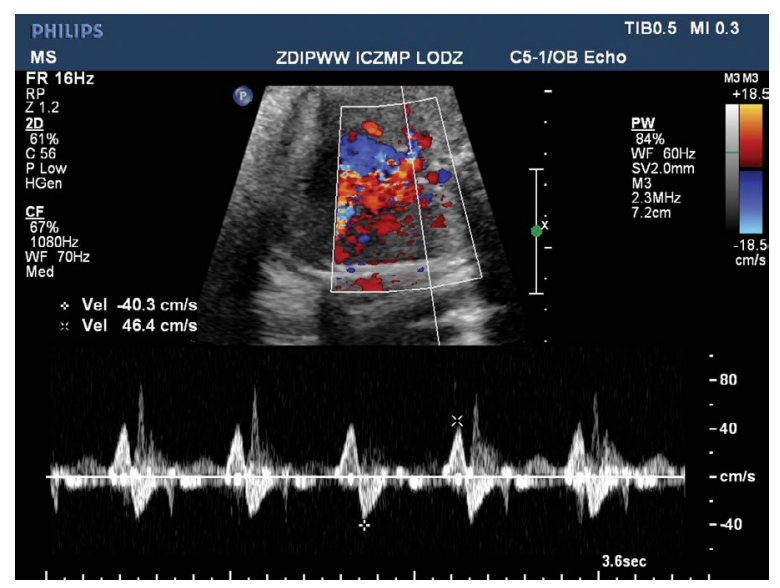

Figure 6. Prenatally predicted severest HLHS with total abnormal pulmonary vein flow. Postnatally confirmed severest HLHS

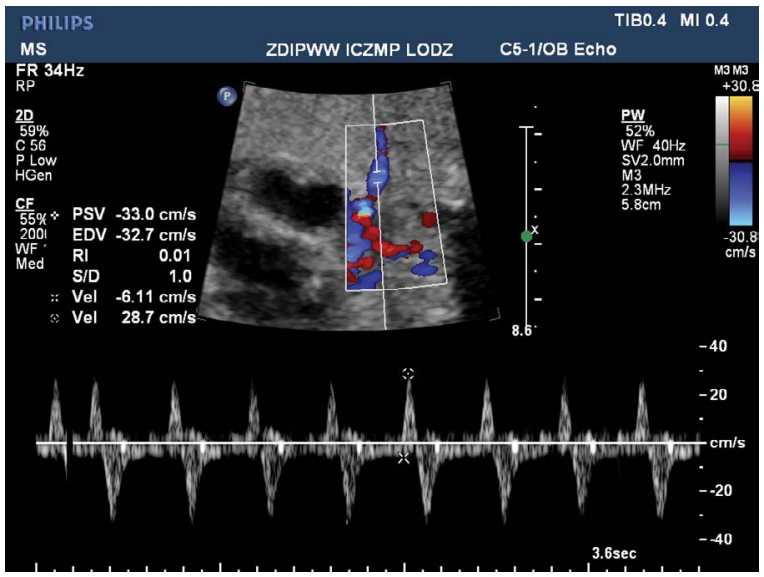

Figure 5. Prenatally predicted severe urgent HLHS with abnormal pulmonary vein flow, VTI $f / r<3$. Postnatally confirmed severe urgent HLHS

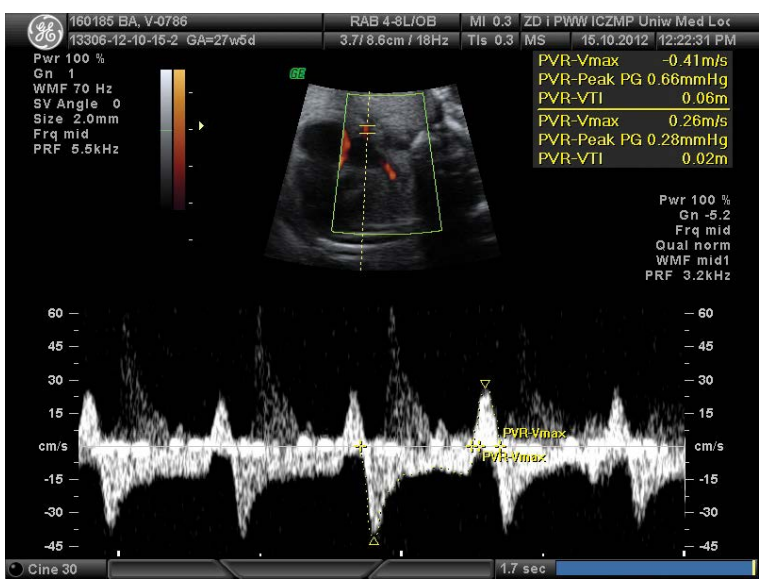

Figure 7. Prenatally predicted severe urgent HLHS with abnormal pulmonary vein flow, VTI f/r between 3-5. Postnatally confirmed severe planned HLHS

\begin{tabular}{|l|l|l|l|l|l|l|l|}
\hline \multicolumn{6}{|c|}{ Table 2. Prenatal qualification of the HLHS fetuses to the group of severe urgent CHD - accuracy of prenatal diagnosis } \\
\hline $\begin{array}{l}\text { True positive } \\
\text { (number) }\end{array}$ & $\begin{array}{l}\text { False positive } \\
\text { (number) }\end{array}$ & $\begin{array}{l}\text { True negative } \\
\text { (number) }\end{array}$ & $\begin{array}{l}\text { False } \\
\text { negative } \\
\text { (number) }\end{array}$ & Sensitivity & Specificity & $\begin{array}{l}\text { Positive } \\
\text { predictive } \\
\text { value }\end{array}$ & $\begin{array}{l}\text { Negative } \\
\text { predictive value }\end{array}$ \\
\hline 2 & 19 & 79 & 0 & $100.00 \%$ & $80.60 \%$ & $9.50 \%$ & $100.00 \%$ \\
\hline
\end{tabular}

ized by a sensitivity close to $100 \%, 94-98 \%$ specificity and positive predictive value of $75-91 \%[22,24]$. In the material we studied, the HLHS fetuses were classified and assigned to respective risk groups depending on the evaluation of the the FO diameter (measured using the 2D Ultrasound and Color Doppler technique), the maximum velocity of blood flow through the FO, and a subjective assessment of the blood flow spectra through the pulmonary veins [6]. This methodology allowed us to identify fetuses with severe urgent HLHS with a sensitivity of $100 \%$ and specificity of $80.6 \%$, but it was associated with a very low positive predictive value of $9.5 \%$ (Tab. 2). M. Taketazu et al. proved that the measurement of the FO diameter in the fetus does not correlate well with its actual diameter in the newborn (Fig. 5, 6). Furthermore, it does not allow us to predict the need for an urgent Rashkind procedure [23]. Therefore, it seems reasonable to use the VTI $\mathrm{f} / \mathrm{r}$ ratio in the pulmonary veins as the main criterion for assigning HLHS fetuses to the group that may require the Rashkind procedure in the first day of life (Fig. 7, 8). Such an approach enables a significant increase in specificity without losing sensitivity. It should be noted, that the criteria used so far have worked very well in diagnosing the severest cases of HLHS with intact atrial septum, with a sensitivity and specificity of $100 \%$. A maternal hyperoxygenation test, which involves inhalation of $100 \%$ oxygen for 10 minutes by the gravida 


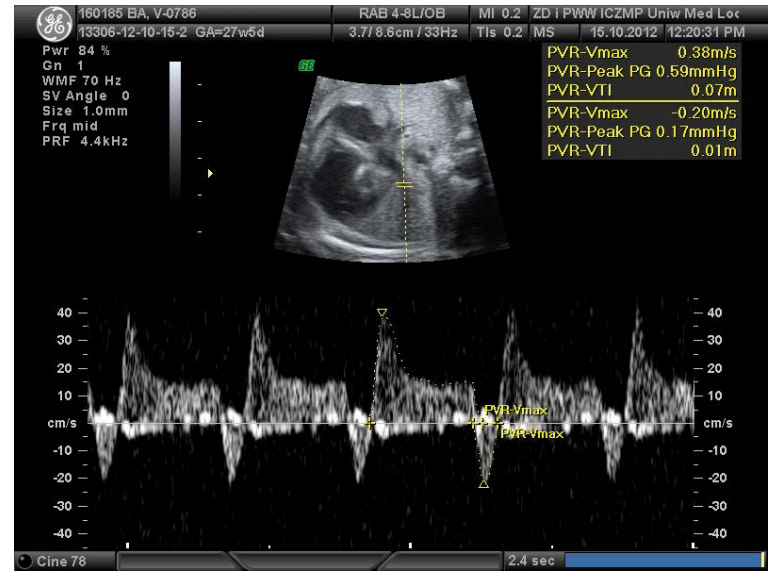

Figure 8. Prenatally predicted severe planned HLHS with VTI f/r 7. Postnatally confirmed severe planned HLHS

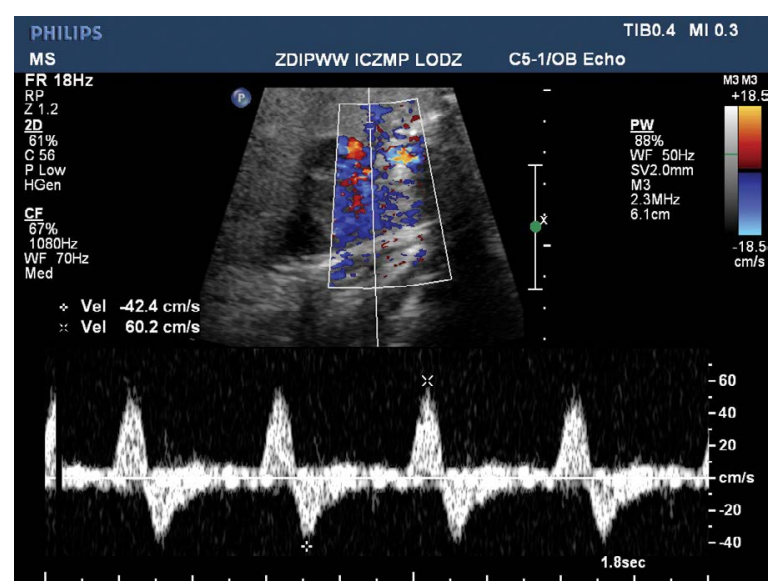

Figure 9. Pulmonary vein flow in $37 \mathrm{hbd}, \mathrm{VTI} \mathrm{f} / \mathrm{r}<3$, predicted severe urgent HLHS

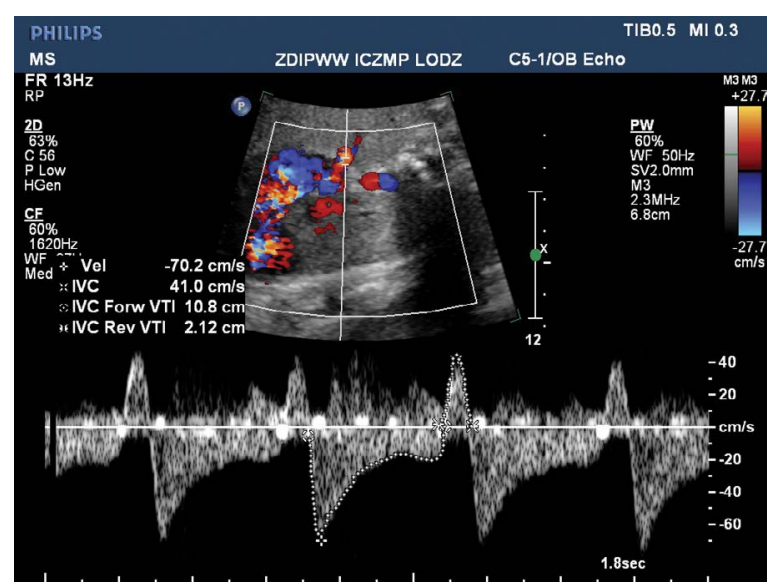

Figure 10. The same patient from figure 7, pulmonary vein flow after mother hyperoxygenation, VTI f/r 5, predicted severe planned HLHS

may be useful in detecting HLHS cases requiring urgent treatment. Enzensberger et al. showed that in fetuses with HLHS and normal inter-atrial communication the maternal hyperoxygenation test results in increased fetal lung per- fusion, leading to a decrease of the pulsatility index of the blood flow spectra in the pulmonary veins. In the fetuses with restrictive $\mathrm{FO}$, the response of the pulmonary veins to maternal hyperoxygenation was significantly less pronounced [25]. The usefulness of hyperoxygenation is still the subject of research. In addition to its diagnostic use, it is postulated that it may have a long-term beneficial therapeutic effect on the hemodynamics of fetuses with CHD $[26,27]$. Observations show, that in cases of longitudinal maternal hyperoxygenation, an improvement in the VTI $\mathrm{f} / \mathrm{r}$ ratio and a change of the HLHS classification from severe urgent to severe planned (from LOC3 to LOC2 according to Donofrio) can be obtained (Fig. 9, 10). So far, these are the only clinical observations and they need to be confirmed by statistical analysis with a larger group of patients.

Low positive predictive value is connected mainly to inclusion criteria based on FO features which appear too sensitive. To improve prediction of severe urgent HLHS the primary focus should be on the pulmonary vein flow, followed by the FO features.

Classification, based on FO restriction, to the severe urgent and severe planned groups was not a good predictor for urgent cardiac intervention (2 urgent interventions in a group of 21 severe urgent patients, with a positive predictive value of 9.5\%). However, this classification influenced the duration of the hospitalization, which tended to be longer in the severe urgent group compared with the severe planned group ( 46.5 days vs 38 days, $p=0.059$ ). Similar observations have not been described in the literature so far.

\section{CONCLUSIONS}

1. Prenatal qualification, based on the features of the foramen ovale, to the group of severe urgent $\mathrm{CHD}$ was characterized by high sensitivity and satisfying specificity, but also by a low positive predictive value.

2. Prenatally diagnosed foramen ovale restriction may be a factor leading to longer hospitalization but is not an indicator of the need for an urgent Rashkind procedure.

3. New classifications of CHDs allowed us to determine the prognosis and to plan the optimal multi-specialized care, which resulted in similar outcomes for the severe planned and severe urgent HLHS patients.

\section{Acknowledgments}

Sponsor: Polish Ministry of Science and Higher Education, Polish Mother's Memorial Hospital- Research Institute- Internal Grant no 2017/III/29-SZB.

\section{REFERENCES}

1. KordjalikP, Respondek-Liberska MH. on the basis of a Nationwide Registry of Fetal Cardiac Pathology www.orpkp.pl. Prenat Cardio. 2013 Sep.;3(3): 18-21.

2. Słodki $M$, Respondek-Liberska M. Proposal of screening fetal heart examination form granted by Polish Ministry of Health Program Kardio-Prenatal 2008. Ginekol Pol. 2009; 80: 466-470. 
3. Sanapo L, Pruetz JD, Słodki M, et al. Fetal echocardiography for planning perinatal and delivery room care of neonates with congenital heart disease. Echocardiography. 2017; 34(12): 1804-1821, doi: 10.1111/echo.13672, indexed in Pubmed: 29287132.

4. Słodki M, Respondek-Liberska M, Pruetz JD, et al. Fetal cardiology: changing the definition of critical heart disease in the newborn. J Perinatol. 2016; 36(8): 575-580, doi: 10.1038/jp.2016.20, indexed in Pubmed: 26963427.

5. Respondek-Liberska M. ATLAS of prenatal heart defects- Selected examples and their clinical significance. ADI Publishers. (PL): 2011.

6. Słodki M, Respondek-Liberska M. New classifications of prenatally diagnosed congenital heart defects and their influence of neonatal survivability. . Prenat Cardio. 2015 Sep.; 5(3): 6-8.

7. Hypoplastic left heart syndrome. Comprehensive Surgical Management of Congenital Heart Disease. 2012, doi: 10.1201/b13620-23.

8. Słodki M. Developing a model of care for pregnant women with congenital heart disease in the fetus on the basis of a new division for prenatal heart defects. Habilitation thesis. Medical University Lodz, PWSZ Plock. 2012

9. Pruetz JD, Carroll C, Trento LU, et al. Outcomes of critical congenital heart disease requiring emergent neonatal cardiac intervention. Prenat Diagn. 2014; 34(12): 1127-1132, doi: 10.1002/pd.4438, indexed in Pubmed: 24947130

10. Vida VL, Bacha EA, Larrazabal A, et al. Hypoplastic left heart syndrome with intact or highly restrictive atrial septum: surgical experience from a single center. Ann Thorac Surg. 2007; 84(2): 581-5; discussion 586, doi: 10.1016/j.athoracsur.2007.04.017, indexed in Pubmed: 17643639.

11. Donofrio MT, Levy RJ, Schuette JJ, et al. Specialized delivery room planning for fetuses with critical congenital heart disease. Am J Cardiol. 2013; 111(5): 737-747, doi: 10.1016/j.amjcard.2012.11.029, indexed in Pubmed: 23291087

12. Glatz JA, Tabbutt S, Gaynor JW, et al. Hypoplastic left heart syndrome with atrial level restriction in the era of prenatal diagnosis. Ann Thorac Surg. 2007; 84(5): 1633-1638, doi: 10.1016/j.athoracsur.2007.06.061, indexed in Pubmed: 17954074.

13. Rychik J, Rome J, Collins M, et al. The hypoplastic left heart syndrome with intact atrial septum: atrial morphology, pulmonary vascular histopathology and outcome. Journal of the American College of Cardiology. 1999; 34(2): 554-560, doi: 10.1016/s0735-1097(99)00225-9.

14. Vlahos AP, Lock JE, McElhinney DB, et al. Hypoplastic left heart syndrome with intact or highly restrictive atrial septum: outcome after neonatal transcatheter atrial septostomy. Circulation. 2004; 109(19): 2326-2330, doi: 10.1161/01.CIR.0000128690.35860.C5, indexed in Pubmed: 15136496.

15. Jacobs $M$, Blackstone $E$, Bailey L. Intermediate survival in neonates with aortic atresia: A multi-institutional study. The Journal of Thoracic and Cardiovascular Surgery. 1998; 116(3): 417-431, doi: 10.1016/s0022-5223(98)70008-x.
16. Moon-Grady AJ, Morris SA, Belfort M, et al. International Fetal Cardiac Intervention Registry. International Fetal Cardiac Intervention Registry: A Worldwide Collaborative Description and Preliminary Outcomes. J Am Coll Cardiol. 2015; 66(4): 388-399, doi: 10.1016/j.jacc.2015.05.037, indexed in Pubmed: 26205597.

17. Jantzen DW, Moon-Grady AJ, Morris SA, et al. Hypoplastic Left Heart Syndrome With Intact or Restrictive Atrial Septum: A Report From the International Fetal Cardiac Intervention Registry. Circulation. 2017; 136(14): 1346-1349, doi: 10.1161/CIRCULATIONAHA.116.025873, indexed in Pubmed: 28864444.

18. Marshall AC, Levine J, Morash D, et al. Results of in utero atrial septoplasty in fetuses with hypoplastic left heart syndrome. Prenat Diagn. 2008; 28(11): 1023-1028, doi: 10.1002/pd.2114, indexed in Pubmed: 18925607.

19. Słodki M, Janiak K, Szaflik K, et al. Fetal echocardiography before and after prenatal aspiration of a fetal ovarian cyst. Ginekol Pol. 2009; 80: 629-631.

20. Słodki M, Janiak K, Szaflik K, et al. Fetal echocardiography in fetal ovarian cysts. Ginekol Pol. 2008; 79: 347-351.

21. Michelfelder E, Gomez C, Border W, et al. Predictive value of fetal pulmonary venous flow patterns in identifying the need for atrial septoplasty in the newborn with hypoplastic left ventricle. Circulation. 2005; 112(19): 2974-2979, doi: 10.1161/CIRCULATIONAHA.105.534180, indexed in Pubmed: 16260632.

22. Divanović $\mathrm{A}, \mathrm{Hor} \mathrm{K}, \mathrm{Cnota}$ J, et al. Prediction and perinatal management of severely restrictive atrial septum in fetuses with critical left heart obstruction: clinical experience using pulmonary venous Doppler analysis. JThorac Cardiovasc Surg. 2011; 141(4): 988-994, doi: 10.1016/j. jtcvs.2010.09.043, indexed in Pubmed: 21130471.

23. Taketazu M, Barrea C, Smallhorn JF, et al. Intrauterine pulmonary venous flow and restrictive foramen ovale in fetal hypoplastic left heart syndrome. J Am Coll Cardiol. 2004; 43(10): 1902-1907, doi: 10.1016/j. jacc.2004.01.033, indexed in Pubmed: 15145119.

24. Donofrio MT, Skurow-Todd K, Berger JT, et al. Risk-stratified postnata care of newborns with congenital heart disease determined by fetal echocardiography. J Am Soc Echocardiogr. 2015; 28(11): 1339-1349, doi: 10.1016/j.echo.2015.07.005, indexed in Pubmed: 26298099.

25. Enzensberger C, Axt-Fliedner R, Degenhardt J, et al. Pulmonary Vasoreactivity to Materno-Fetal Hyperoxygenation Testing in Fetuses with Hypoplastic Left Heart. Ultraschall Med. 2016; 37(2): 195-200, doi: 10.1055/s-0034-1385668, indexed in Pubmed: 25607629.

26. Kohl T. Chronic intermittent materno-fetal hyperoxygenation in late gestation may improve on hypoplastic cardiovascular structures associated with cardiac malformations in human fetuses. Pediatr Cardiol. 2010; 31(2): 250-263, doi: 10.1007/s00246-009-9600-5, indexed in Pubmed: 20024652.

27. Schidlow DN, Donofrio MT. Prenatal Maternal Hyperoxygenation Testing and Implications for Critical Care Delivery Planning among Fetuses with Congenital Heart Disease: Early Experience. Am J Perinatol. 2018; 35(1): 16-23, doi: 10.1055/s-0037-1603991, indexed in Pubmed: 28746973. 